\title{
Superior Cerebellar Artery
}

National Cancer Institute

\section{Source}

National Cancer Institute. Superior Cerebellar Artery. NCI Thesaurus. Code C33669.

The arteries arising from the basilar artery that supply the upper surface of the cerebellum, pia mater, pineal gland, valve of Vieussens and velum interpositum. 